\title{
Effects of Fe, W and Mo on Kinetics of Discontinuous Precipitation in the Ni-Cr System
}

\author{
Shigeki Ueta ${ }^{1}$, Masahiro Hida $^{2}$ and Masanori Kajihara ${ }^{3, *}$ \\ ${ }^{1}$ Special Steel Laboratory, R\&D Center, Daido Steel Co., Ltd., Nagoya 457-8545, Japan \\ ${ }^{2}$ Graduate School, Tokyo Institute of Technology, Yokohama 226-8502, Japan \\ ${ }^{3}$ Department of Materials Science and Engineering, Tokyo Institute of Technology, Yokohama 226-8502, Japan
}

The effects of $\mathrm{Fe}, \mathrm{W}$ and Mo on the kinetics of discontinuous precipitation in the Ni-Cr system were experimentally examined using a binary $\mathrm{Ni}-38 \mathrm{Cr}$ alloy and ternary $\mathrm{Ni}-38 \mathrm{Cr}-0.9 \mathrm{Fe}, \mathrm{Ni}-38 \mathrm{Cr}-3.2 \mathrm{~W}$ and $\mathrm{Ni}-38 \mathrm{Cr}-1.7 \mathrm{Mo}$ alloys. These alloys were homogenized at $1423 \mathrm{~K}$ for $3 \mathrm{~h}$, solution treated at $1423 \mathrm{~K}$ for $1 \mathrm{~h}$, and then isothermally annealed in the temperature range of $873-1023 \mathrm{~K}$ for various times up to $2300 \mathrm{~h}$. Due to the solution heat treatment, all the alloys show the polycrystalline single-phase microstructure of the Ni-rich solid-solution $(\gamma)$ phase with the face-centered cubic structure. During isothermal annealing, however, the cell of the lamellar microstructure consisting of the $\gamma$ phase and the Cr-rich solid-solution $(\alpha)$ phase with the body-centered cubic structure is formed along the grain boundary of the $\gamma$ matrix and then grows into the $\gamma$ matrix. At each annealing temperature, the migration distance of the moving cell boundary is proportional to the annealing time. Hence, the growth rate of the cell is constant independent of the annealing time. The growth rate and the interlamellar spacing of the cell almost monotonically increase with increasing annealing temperature at $873-1023 \mathrm{~K}$. The cell growth is decelerated by W and Mo but not by Fe. The deceleration is more remarkable for Mo than for W. A kinetic model for the binary discontinuous precipitation controlled by boundary diffusion was used to analyze quantitatively the experimental result. According to the analysis, $\mathrm{W}$ and Mo retard the boundary diffusion of Cr along the moving cell boundary, but Fe slightly hastens that. Such influence of the alloying component on the boundary diffusion is ascribable to the thermodynamic interaction between $\mathrm{Cr}$ and the alloying component in the moving cell boundary. As a consequence, it is concluded that the retardation of the $\mathrm{Cr}$ boundary diffusion causes the deceleration of the cell growth. [doi:10.2320/matertrans.M2012132]

(Received April 9, 2012; Accepted July 19, 2012; Published September 5, 2012)

Keywords: nickel-base superalloy, discontinuous precipitation, boundary diffusion

\section{Introduction}

Nickel-base super alloys containing around 40 mass $\%$ of $\mathrm{Cr}$ and around 4 mass $\%$ of $\mathrm{Al}$ possess superior mechanical properties and heat-resistance at high temperatures and excellent nonmagnetism even at very low temperatures. The capabilities for this type of Ni-base super alloy have been studied by many investigators. ${ }^{1-6)}$ Under usual application conditions, the super alloy indicates the lamellar microstructure composed of the Ni-rich solid-solution $(\gamma)$ phase with the face-centered cubic (fcc) structure and the Cr-rich solid-solution $(\alpha)$ phase with the body-centered cubic (bcc) structure. Furthermore, fine particles of the $\mathrm{Ni}_{3} \mathrm{Al}\left(\gamma^{\prime}\right)$ phase with the $\mathrm{Ll}_{2}$ structure are dispersed in the lamellar microstructure. The remarkable capabilities of the super alloy are attributed to such a multiphase microstructure. The formation of the multiphase microstructure has been experimentally examined by various researchers. ${ }^{7-9)}$ For instance, Kawase et al. ${ }^{9)}$ observed the crystallographic orientation relationships among the $\alpha, \gamma$ and $\gamma$ phases by transmission electron microscopy (TEM). In this experiment, a polycrystalline $\mathrm{Ni}-$ $39 \mathrm{Cr}-3.8 \mathrm{Al}$ alloy was homogenized at $1523 \mathrm{~K}$ for $1 \mathrm{~h}$ and then isothermally annealed at temperatures of 723-1273 K for various times up to $3.8 \mathrm{~h}$. According to their observation, fine particles of the $\gamma^{\prime}$ phase are formed in the $\gamma$ matrix by continuous precipitation in the early stages of isothermal annealing at temperatures of $723-1123 \mathrm{~K}$ and the parallel orientation relationship of $\{111\}_{\gamma} / /\{111\}_{\gamma^{\prime}}$ and $\langle 110\rangle_{\gamma} / /$ $\langle 110\rangle_{\gamma^{\prime}}$ holds between the $\gamma$ and $\gamma$ phases. During isothermal annealing, however, the cell consisting of the $\alpha$ and $\gamma$ lamellae is produced at the grain boundary of the $\gamma$ matrix by

*Corresponding author, E-mail: kajihara@materia.titech.ac.jp discontinuous precipitation and grows into the $\gamma$ matrix. Also in the cell, fine particles of the $\gamma$ phase are dispersed in the $\gamma$ lamella as well as the $\gamma$ matrix, and the parallel orientation relationship is realized between the $\gamma$ lamella and the $\gamma$ particle. In contrast, the Kurdjumov-Sachs relationship of $\{111\}_{\gamma} / /\{110\}_{\alpha}$ and $\langle 110\rangle_{\gamma} / /\langle 111\rangle_{\alpha}$ is actualized between the $\gamma$ and $\alpha$ lamellae. Since special crystallographic orientation relationships hardly exist between the adjacent $\gamma$ lamella and matrix along the moving cell boundary, the $\gamma$ particle in the $\gamma$ matrix should dissolve in the moving cell boundary to precipitate again in the $\gamma$ lamella with the parallel orientation relationship. The kinetics of the discontinuous precipitation with such complex reactions in the $\mathrm{Ni}-39 \mathrm{Cr}-3.8 \mathrm{Al}$ alloy was experimentally observed by Kawase et al. ${ }^{9)}$ Their observation indicates that the addition of Al with 3.8 mass $\%$ into the $\mathrm{Ni}-39 \mathrm{Cr}$ alloy diminishes the interlamellar spacing of the cell by one order of magnitude and accelerates the growth of the cell by three orders of magnitude. Unfortunately, however, no quantitative explanation is available for such effects of Al.

To find the quantitative explanation, the influence of $\mathrm{Al}$ on the kinetics of the discontinuous precipitation in the ternary $\mathrm{Ni}-\mathrm{Cr}-\mathrm{Al}$ system was experimentally observed in a previous study. ${ }^{10)}$ In this experiment, $\mathrm{Ni}-38 \mathrm{Cr}-\mathrm{Al}$ alloys with $\mathrm{Al}$ concentrations of 3.8 and 4.2 mass $\%$ were isothermally annealed at temperatures of $773-1073 \mathrm{~K}$, and then the microstructure of the alloy was observed by a metallographical technique. According to the observation, the migration distance of the moving cell boundary is proportional to the annealing time at each annealing temperature. Thus, the growth rate of the cell is constant independent of the annealing time. The growth rate and the interlamellar spacing of the cell monotonically increase with increasing 
annealing temperature at $773-1073 \mathrm{~K}$. The kinetic model proposed by Aaronson and $\mathrm{Liu}^{11}$ ) was used to analyze quantitatively the observation. Although the discontinuous precipitation in the ternary $\mathrm{Ni}-38 \mathrm{Cr}-\mathrm{Al}$ alloys occurs in a complicated manner as reported by Kawase et al., ${ }^{9)}$ the analysis indicates that the growth of the lamellar cell is controlled by the boundary diffusion of $\mathrm{Cr}$ along the moving cell boundary and the acceleration effect of $\mathrm{Al}$ is attributed to the supersaturation of $\mathrm{Cr}$ in the $\gamma$ matrix enhanced by the continuous precipitation of the $\gamma^{\prime}$ phase. In the materials industry, however, slower growth of the cell is more desirable to control accurately the microstructure of the alloy. Thus, the $\mathrm{Al}$ effect has to be compensated by addition of other alloying components into the alloy. However, no reliable experimental information is available for such alloying components. In the present study, effects of $\mathrm{Fe}, \mathrm{W}$ and Mo on the kinetics of the discontinuous precipitation were experimentally examined by the technique used in a previous study. ${ }^{10}$ ) To exclude the influence of the continuous precipitation on the kinetics, however, attention was focused on the growth behavior of the cell in the $\mathrm{Ni}-\mathrm{Cr}-X$ system without $\mathrm{Al}$. In the experiment, ternary $\mathrm{Ni}-38 \mathrm{Cr}-0.9 \mathrm{Fe}, \mathrm{Ni}-38 \mathrm{Cr}-3.2 \mathrm{~W}$ and $\mathrm{Ni}-38 \mathrm{Cr}-1.7 \mathrm{Mo}$ alloys as well as a binary $\mathrm{Ni}-38 \mathrm{Cr}$ alloy were isothermally annealed in the temperature range of $873-1023 \mathrm{~K}$. This temperature range is relevant to a practical heat treatment in the materials industry. If a large amount of component $X$ is added into the Ni-Cr alloy, the composition dependence of the kinetics can be exaggerated. However, the large-amount addition may deduce formation of different phases and thus change the resultant microstructure. To avoid such a microstructural change, the addition of component $X$ was restricted within the solubility ranges of the $\alpha$ and $\gamma$ phases. ${ }^{12,13)}$ The rate-controlling process for the cell growth was discussed on the basis of the observation.

\section{Experimental}

A binary $\mathrm{Ni}-38 \mathrm{Cr}$ alloy and ternary $\mathrm{Ni}-38 \mathrm{Cr}-0.9 \mathrm{Fe}, \mathrm{Ni}-$ $38 \mathrm{Cr}-3.2 \mathrm{~W}$ and $\mathrm{Ni}-38 \mathrm{Cr}-1.7 \mathrm{Mo}$ alloys were prepared as $150 \mathrm{~kg}$ ingots in a vacuum by an induction melting technique. The Ni-Cr, Ni-Cr-Fe, Ni-Cr-W and Ni-Cr-Mo alloys are called alloys A1, A2, A3 and A4, respectively. The chemical compositions of these alloys were measured by chemical analysis. The raw result is listed in Table 1 . In this table, the concentration of each component is shown in mass\%. Here, a small amount of $\mathrm{C}$ contributes to deoxidization, and that of $\mathrm{B}$ improves hot workability. The ingots were homogenized in an ambient atmosphere at $1423 \mathrm{~K}$ for $3 \mathrm{~h}(10.8 \mathrm{ks})$ and then hot forged into columnar bars with a diameter of $18 \mathrm{~mm}$. Due to the high $\mathrm{Cr}$ concentration, the alloy is protected from internal oxidation by a thin surface layer of $\mathrm{Cr}_{2} \mathrm{O}_{3}$. Disk specimens with a thickness of $10 \mathrm{~mm}$ and a diameter of $18 \mathrm{~mm}$ were cut from the forged bar and then solution treated in an ambient atmosphere at $1423 \mathrm{~K}$ for $1 \mathrm{~h}(3.6 \mathrm{ks})$, followed by water quenching. Each solution treated specimen was isothermally annealed in an ambient atmosphere at temperatures of $873-1023 \mathrm{~K}$ for various periods up to $2300 \mathrm{~h}$ $(8.28 \mathrm{Ms})$, followed by water quenching. Hereafter, the annealing temperature and time are denoted by $T$ and $t$, respectively.
Table 1 Chemical compositions of alloys A1-A4 in mass\%.

\begin{tabular}{cccccccc}
\hline Alloy & $\mathrm{Ni}$ & $\mathrm{Cr}$ & $\mathrm{Fe}$ & $\mathrm{W}$ & \multicolumn{1}{c}{ Mo } & $\mathrm{C}$ & $\mathrm{B}$ \\
\hline $\mathrm{A} 1$ & 61.17 & 38.78 & 0.02 & $<0.01$ & $<0.01$ & 0.007 & 0.003 \\
$\mathrm{~A} 2$ & 60.31 & 38.75 & 0.91 & $<0.01$ & $<0.01$ & 0.010 & 0.003 \\
$\mathrm{~A} 3$ & 58.38 & 38.33 & 0.02 & 3.23 & 0.03 & 0.005 & 0.004 \\
$\mathrm{~A} 4$ & 59.72 & 38.58 & 0.02 & $<0.01$ & 1.66 & 0.006 & 0.003 \\
\hline
\end{tabular}

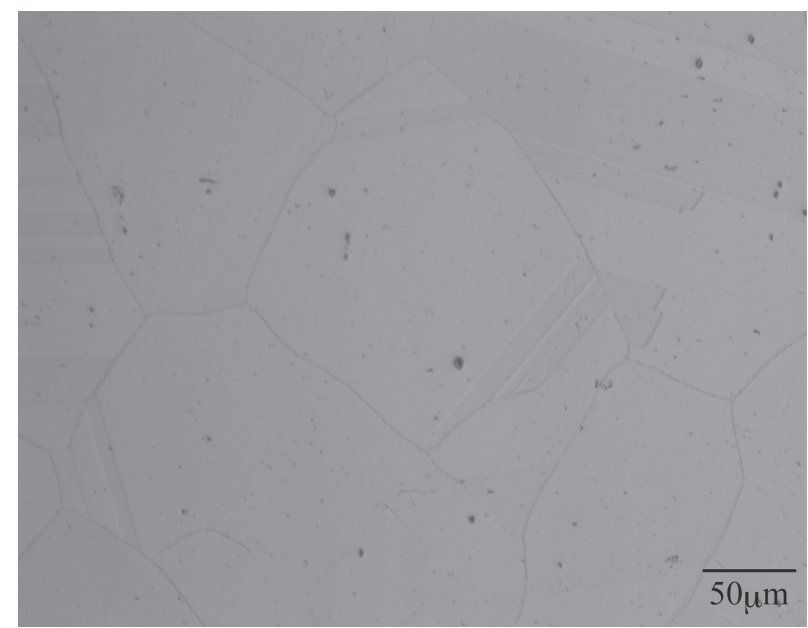

Fig. 1 OM photograph of cross-section for alloy A1 after solution heat treatment.

Cross-sections of the annealed specimen were mechanically polished on \#800-4000 emery papers and then finished using diamond with a diameter of $1 \mu \mathrm{m}$. The finished crosssection was electrolytically etched with an etchant consisting of $10 \mathrm{vol} \%$ of oxalic acid and $90 \mathrm{vol} \%$ of distilled water at room temperature. The microstructure of the cross-section was observed by optical microscopy (OM) and scanning electron microscopy (SEM).

\section{Results and Discussion}

\subsection{Microstructure}

A typical OM photograph of the cross-section for the solution treated specimen of alloy A1 is shown in Fig. 1. As can be seen, the polycrystalline single-phase microstructure of the $\gamma$ phase is realized for alloy A1 by the solution heat treatment. Such a single-phase microstructure was actualized also for alloys A2-A4. On the other hand, small dark particles are slightly distributed in the $\gamma$ matrix. Since the concentration of $\mathrm{Cr}$ is very high for alloys $\mathrm{A} 1-\mathrm{A} 4$, the small dark particle may be a chromium oxide formed during induction melting. The mean grain size of the $\gamma$ matrix is about $150 \mu \mathrm{m}$ for these alloys.

OM photographs of the cross-section for the specimens annealed at $T=923 \mathrm{~K}$ for $t=1000 \mathrm{~h}(3.6 \mathrm{Ms})$ are indicated in Fig. 2. Figure 2(a)-2(d) shows the photographs of alloys A1-A4, respectively. Two regions with bright and dark contrasts are recognized in Fig. 2. The area of the dark region is smaller for Fig. 2(c) and 2(d) than for Fig. 2(a) and 2(b) but slightly greater for Fig. 2(c) than for Fig. 2(d). A typical SEM photograph of cells in alloy A2 with $T=973 \mathrm{~K}$ and $t=1000 \mathrm{~h}(3.6 \mathrm{Ms})$ is shown in Fig. 3. In this figure, the 

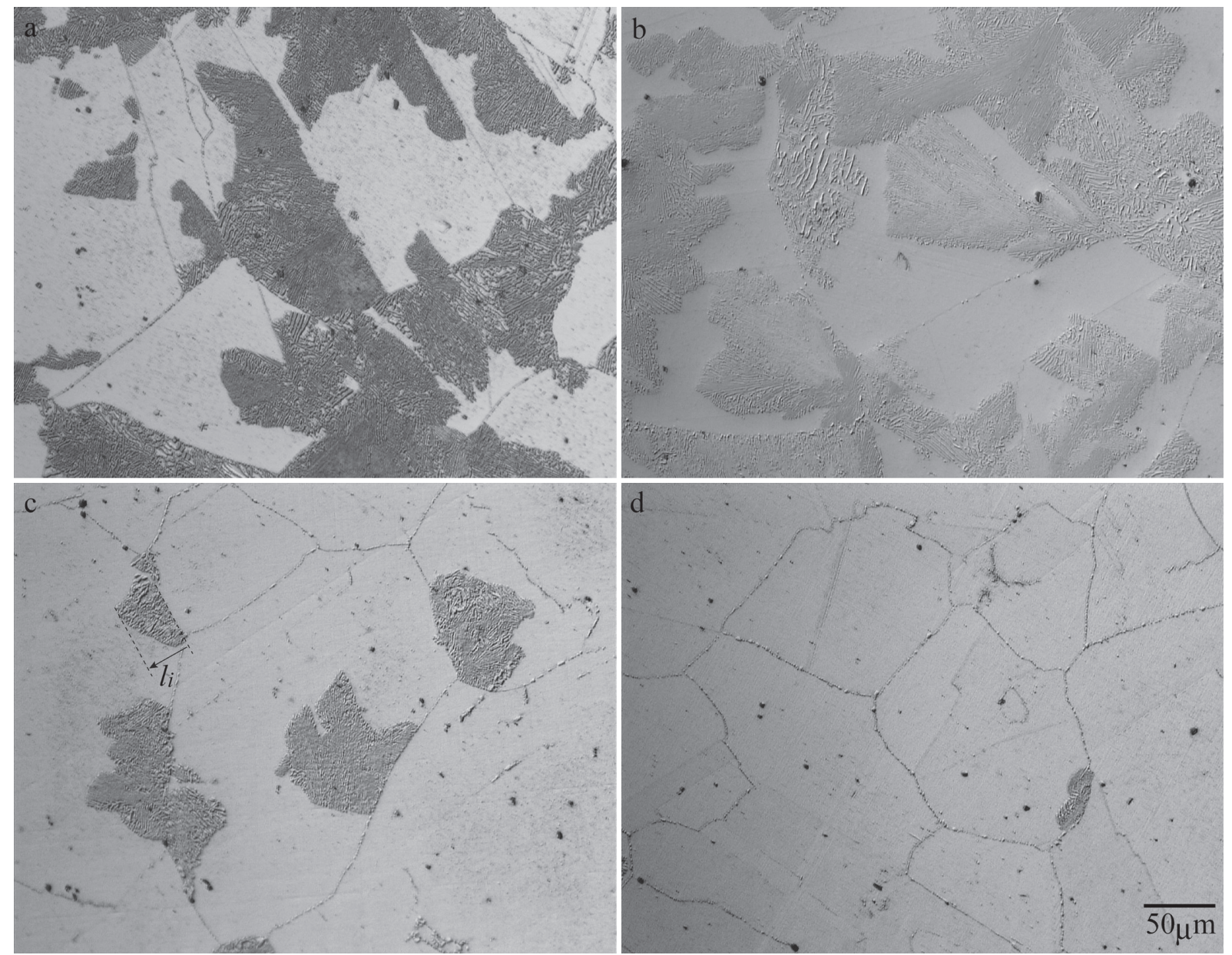

Fig. 2 OM photographs of cross-section after isothermal annealing at $T=923 \mathrm{~K}$ for $t=1000 \mathrm{~h}(3.6 \mathrm{Ms})$ : (a) alloy A1, (b) alloy A2, (c) alloy A3 and (d) alloy A4.

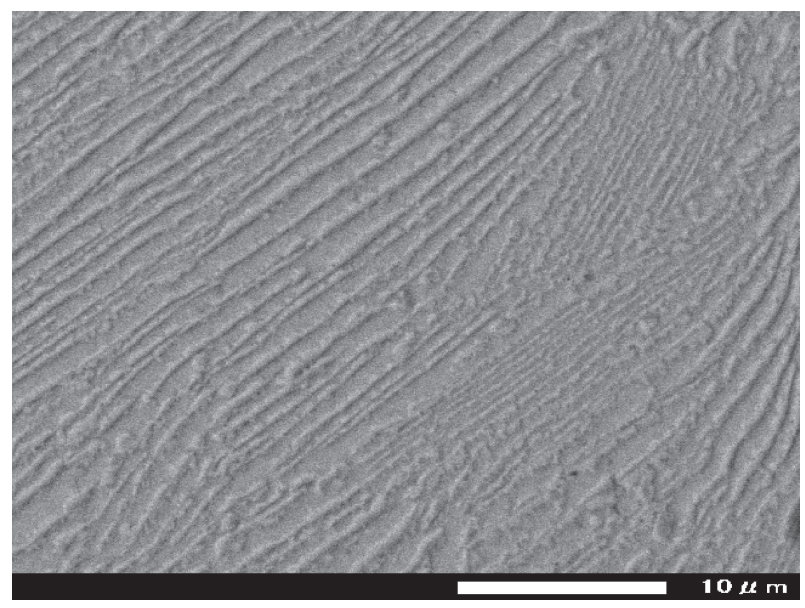

Fig. 3 SEM photograph of the cell in alloy A2 annealed at $T=973 \mathrm{~K}$ for $t=1000 \mathrm{~h}(3.6 \mathrm{Ms})$.

bright and dark lamellae are the $\alpha$ and $\gamma$ phases, respectively, and the $\alpha$ and $\gamma$ lamellae in each cell are almost parallel to each other. Such cells were formed by discontinuous precipitation according to the following reaction: $\gamma_{0} \rightarrow$ $\gamma+\alpha$, where $\gamma_{0}$ is an untransformed matrix phase supersaturated with a solute, $\gamma$ is the matrix phase depleted with the solute, and $\alpha$ is a precipitate phase. Discontinuous

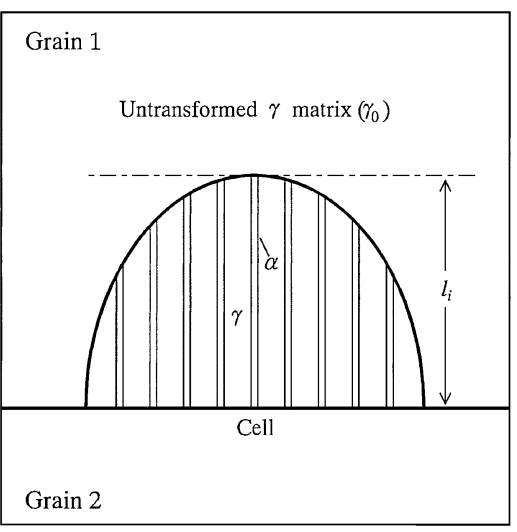

Fig. 4 Schematic drawing of cross-sectional microstructure of isolated cell.

precipitation is known to occur in many alloy systems. The mechanism of discontinuous precipitation is discussed in detail by Manna et al. ${ }^{14)}$ and thus not repeatedly described in the present article.

\subsection{Growth behavior of cell}

A cross-sectional microstructure of an isolated cell is schematically depicted in Fig. 4. From OM photographs like Fig. 2, the maximum distance $l_{i}$ between the stationary grain boundary of the $\gamma$ matrix and the moving cell boundary for 
(a)

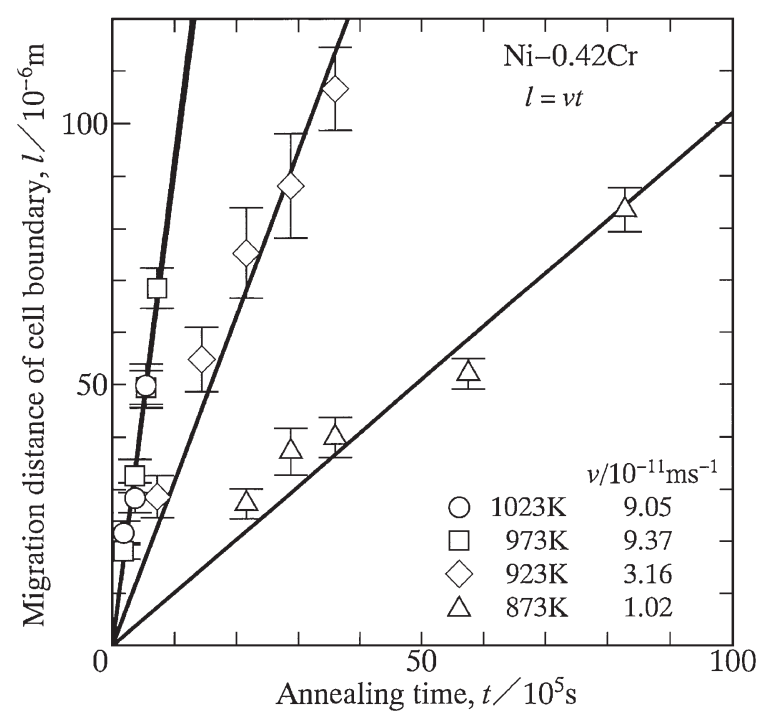

(c)

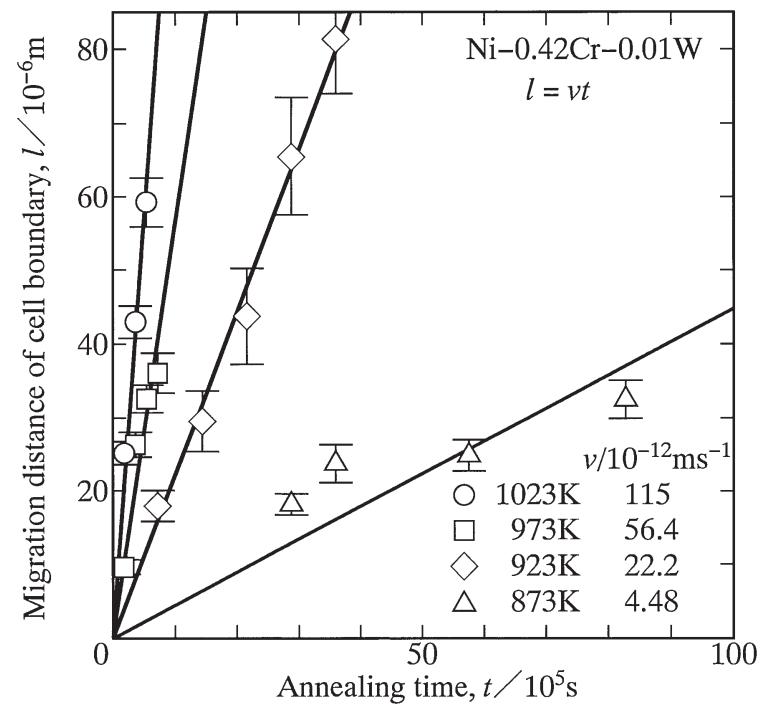

(b)

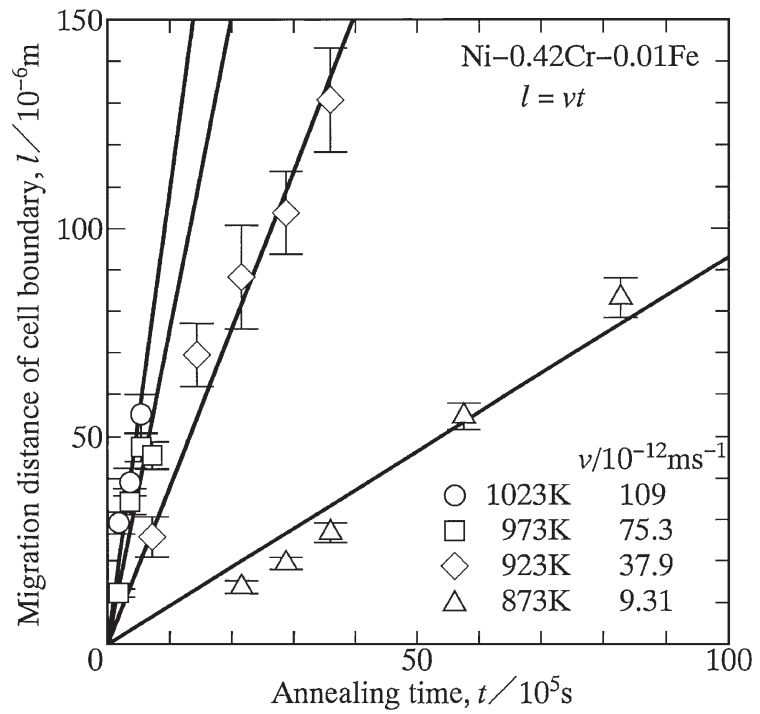

(d)

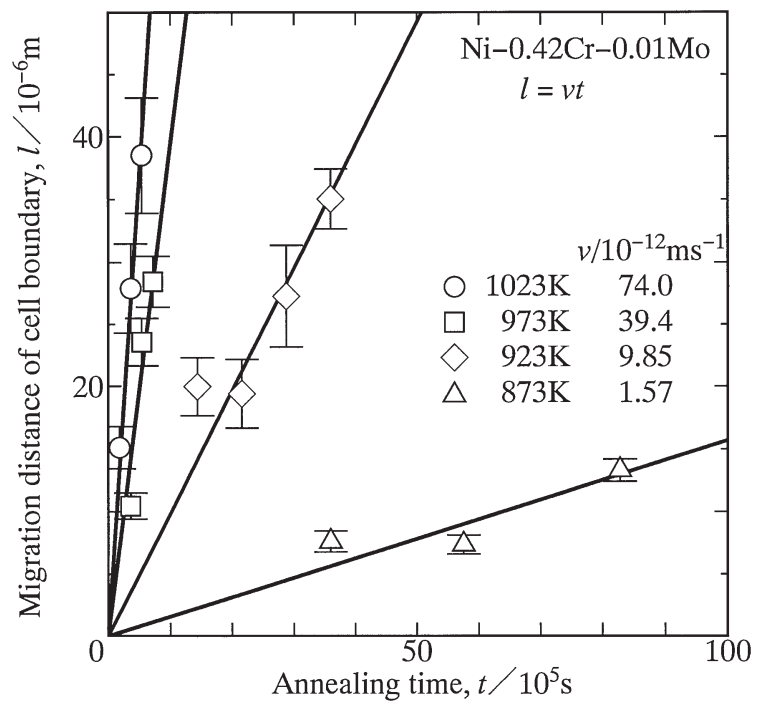

Fig. 5 The migration distance $l$ of the moving cell boundary versus the annealing time $t$ at $T=873-1023 \mathrm{~K}$ : (a) alloy A1, (b) alloy A2, (c) alloy A3 and (d) alloy A4. Straight lines indicate the calculations from eq. (2).

each isolated cell was determined for forty different moving cell boundaries, and then the mean value $l$ of $l_{i}$ was evaluated by the following equation.

$$
l=\frac{1}{N} \sum_{i=1}^{N} l_{i}
$$

Here, $N=40$. The distance $l_{i}$ is shown for a typical isolatedcell in Fig. 2(c). According to the treatment reported by Gust et al., ${ }^{15)} l$ indicates the mean migration distance of the moving cell boundary. This treatment was adopted also in the present study. The evaluation is shown in Fig. 5. Figure 5(a)-5(d) indicates the results of alloys A1-A4, respectively. In Table 1, the raw result of the chemical analysis for the concentration of each component in the alloy is shown in mass \%. Neglecting minor components, the concentration in mass $\%$ was converted into the mol fraction. The result is indicated in Table 2. In this table, $x_{i}^{0}$ stands for the mol fraction of component $i$ in each alloy. Hereafter, the mol fraction is used to describe the chemical composition. In Fig. 5, the ordinate and the
Table 2 Mol fraction $x_{i}^{0}$ of component $i$ for alloys A1-A4.

\begin{tabular}{ccccc}
\hline Alloy & $X$ & $x_{\mathrm{Ni}}^{0}$ & $x_{\mathrm{Cr}}^{0}$ & $x_{X}^{0}$ \\
\hline A1 & - & 0.5830 & 0.4170 & - \\
A2 & $\mathrm{Fe}$ & 0.5744 & 0.4165 & 0.0091 \\
$\mathrm{~A} 3$ & $\mathrm{~W}$ & 0.5688 & 0.4212 & 0.0100 \\
A4 & Mo & 0.5728 & 0.4175 & 0.0098 \\
\hline
\end{tabular}

abscissa show the migration distance $l$ and the annealing time $t$, respectively, and various open symbols with error bars indicate the results at different annealing temperatures. Hereafter, the error bar stands for the standard error of the mean value. As can be seen, most of the open symbols are located well on a straight line at each annealing temperature. Thus, the migration distance $l$ of the moving cell boundary is proportional to the annealing time $t$ as follows.

$$
l=v t
$$




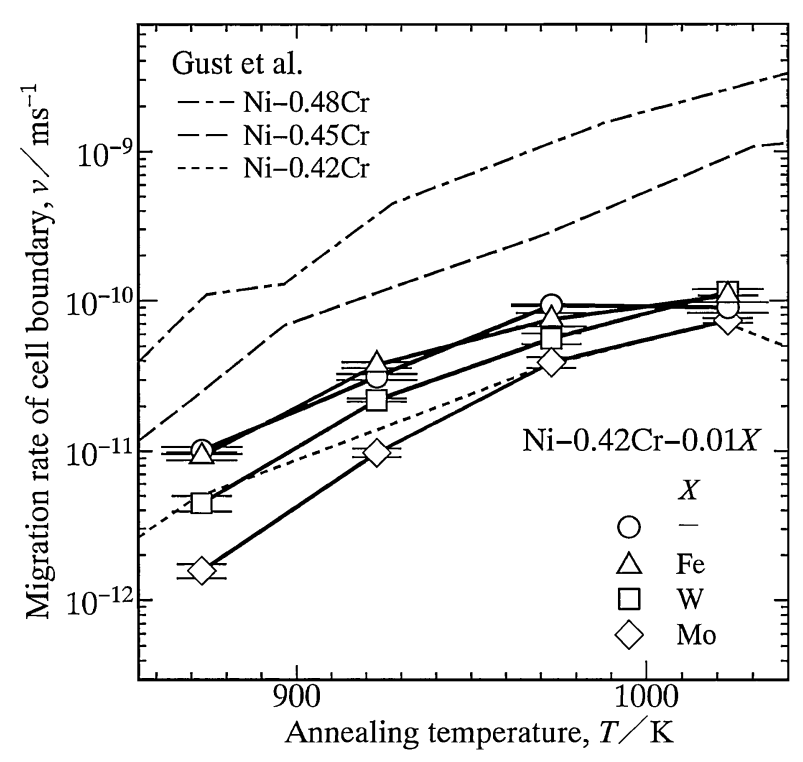

Fig. 6 The migration rate $v$ of the moving cell boundary versus the annealing temperature $T$ for alloys A1, A2, A3 and A4 shown as open circles, triangles, squares and rhombuses, respectively, with error bars. The corresponding results of alloys A5, A6 and $\mathrm{A} 7^{15)}$ are also indicated as thin dotted, dashed and dashed-and-dotted lines, respectively.

In eq. (2), the proportionality coefficient $v$ corresponds to the migration rate of the moving cell boundary. The mean value of $v$ was estimated from the open symbols in Fig. 5 by the least-squares method as shown with the straight lines. The values of $v$ estimated for alloys $\mathrm{A} 1, \mathrm{~A} 2, \mathrm{~A} 3$ and $\mathrm{A} 4$ are plotted as open circles, triangles, squares and rhombuses, respectively, with error bars against the annealing temperature $T$ in Fig. 6. In this figure, the corresponding results of the binary $\mathrm{Ni}-0.42 \mathrm{Cr}, \mathrm{Ni}-0.45 \mathrm{Cr}$ and $\mathrm{Ni}-0.48 \mathrm{Cr}$ alloys reported by Gust et al. ${ }^{15)}$ are indicated as thin dotted, dashed and dashed-and-dotted lines, respectively. The $\mathrm{Ni}-0.42 \mathrm{Cr}$, $\mathrm{Ni}-0.45 \mathrm{Cr}$ and $\mathrm{Ni}-0.48 \mathrm{Cr}$ alloys are hereafter called alloys A5, A6 and A7, respectively. For alloys A2-A4, the migration rate $v$ monotonically increases with increasing annealing temperature $T$. On the other hand, for alloy A1, $v$ reaches the maximum value at $T=973 \mathrm{~K}$ and becomes slightly smaller at $T=1023 \mathrm{~K}$ than at $T=973 \mathrm{~K}$. At most of the annealing temperatures, $v$ is close to each other between alloys A1 and A2 but smaller for alloys A3 and A4 than for alloys $\mathrm{A} 1$ and $\mathrm{A} 2$. Thus, the addition of $X=\mathrm{W}$ or $X=\mathrm{Mo}$ with $x_{X}^{0}=0.01$ into the $\mathrm{Ni}-0.42 \mathrm{Cr}$ alloy decelerates the growth of the cell. The deceleration is more remarkable for $X=$ Mo than for $X=\mathrm{W}$. At $T=873 \mathrm{~K}, v$ is almost one order of magnitude smaller for alloy A4 than for alloy A1. Although $v$ is close to each other between alloys A1 and A5 at $T=1023 \mathrm{~K}$, it is slightly smaller for alloy A5 than for alloy A1 at $T=873-973 \mathrm{~K}$. Among alloys A5-A7, $v$ gradually increases with increasing $\mathrm{Cr}$ concentration. Hence, the higher $\mathrm{Cr}$ concentration is detrimental to the deceleration of the cell growth. According to the result by Gust et al., ${ }^{15)}$ the incubation period for nucleation of cell was clearly observed at some annealing temperatures for each alloy. On the other hand, the open symbols are slightly scattered in Fig. 5. Hence, it cannot be conclusively determined whether the incubation period appears in Fig. 5.

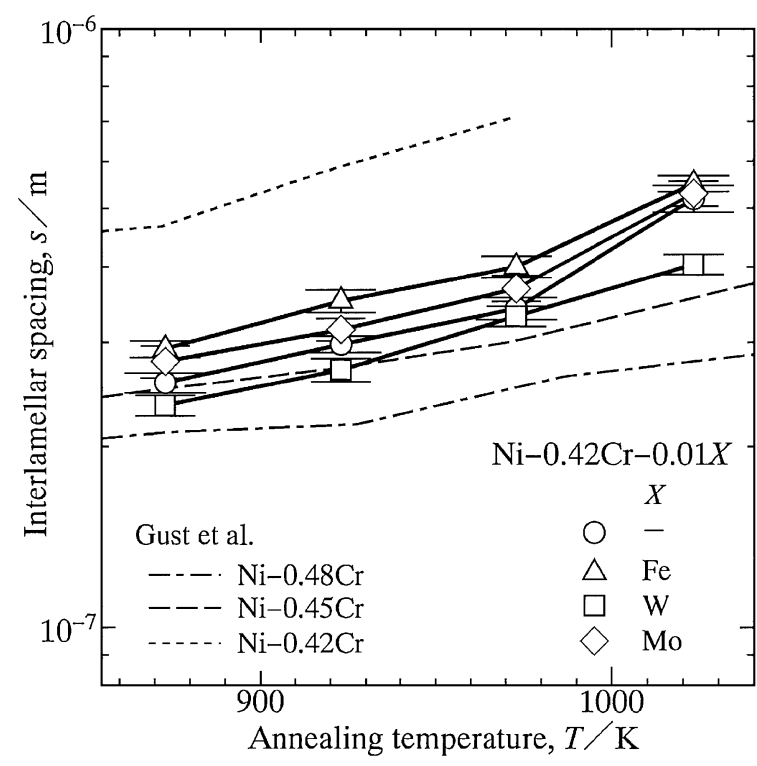

Fig. 7 The interlamellar spacing $s$ of the cell versus the annealing temperature $T$ for alloys A1, A2, A3 and A4 shown as open circles, triangles, squares and rhombuses, respectively, with error bars. The corresponding results of alloys A5, A6 and A $7^{15)}$ are also indicated as thin dotted, dashed and dashed-and-dotted lines, respectively.

From SEM photographs like Fig. 3, the interlamellar spacing $s_{i}$ between the neighboring $\alpha$ lamellae in the cell on the cross-section was determined for forty different cells, and then the mean value $s_{\mathrm{m}}$ of $s_{i}$ was evaluated by the following equation.

$$
s_{\mathrm{m}}=\frac{1}{N} \sum_{i=1}^{N} s_{i}
$$

Like eq. (1), $N=40$. It is reported by Saltykov ${ }^{16)}$ that $s_{\mathrm{m}}$ is related with $s$ as follows for pearlite with a constant interlamellar spacing $s$.

$$
s=\frac{s_{\mathrm{m}}}{2}
$$

According to his metallographical treatment, ${ }^{16)}$ the mean true interlamellar spacing $s$ was evaluated from eq. (4) using the value of $s_{\mathrm{m}}$ experimentally determined on the cross-section. The results for alloys A1, A2, A3 and A4 are plotted as open circles, triangles, squares and rhombuses, respectively, with error bars against the annealing temperature $T$ in Fig. 7. In this figure, the corresponding results of alloys A5, A6 and $\mathrm{A} 7^{15)}$ are indicated as thin dotted, dashed and dashed-anddotted lines, respectively. For all the alloys, $s$ monotonically increases with increasing annealing temperature $T$ at $T=$ $873-1023 \mathrm{~K}$. Although $s$ is the largest for alloy A2 but the smallest for alloy A3, it is not so dissimilar among alloys A1-A4. On the other hand, $s$ is slightly greater for alloy A5 than for alloy A1. For alloys A5-A7, $s$ gradually decreases with increasing $\mathrm{Cr}$ concentration. Even in this case, however, the difference between alloys A5 and A7 is much smaller for $s$ in Fig. 7 than for $v$ in Fig. 6.

\subsection{Kinetic analysis}

Various kinetic models for discontinuous precipitation in binary alloy systems have been proposed by many 


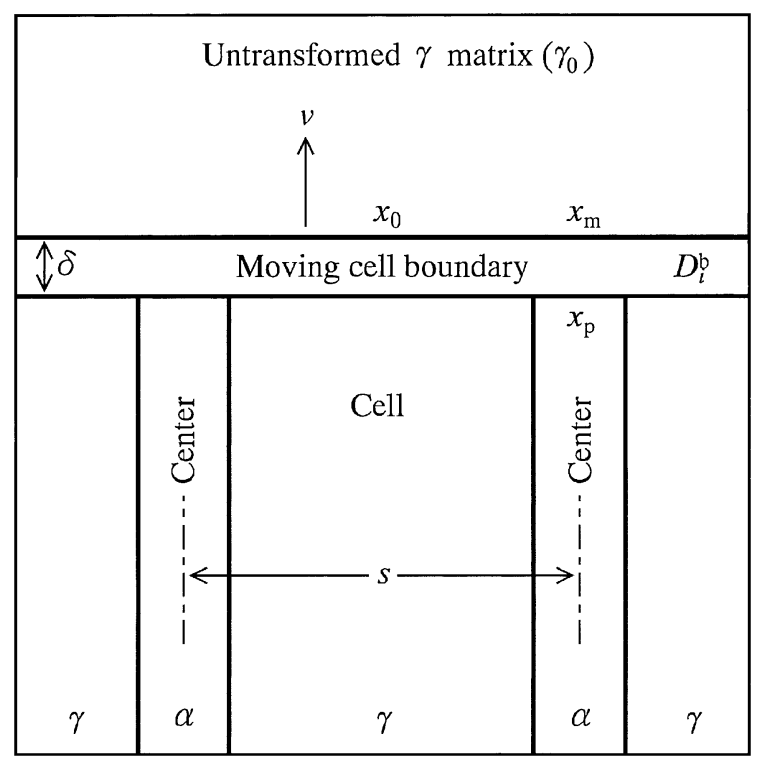

Fig. 8 Schematic drawing of the moving cell boundary for the cell consisting of the $\gamma$ and $\alpha$ lamellae.

investigators. ${ }^{11,17-27)}$ In order for the model to express accurately the kinetics, many parameters are necessary. The more the parameters are adopted, the better the accuracy of model becomes. However, some of the parameters may not be reliably estimated in a highly sophisticated model. A kinetic model for the discontinuous precipitation controlled by boundary diffusion was proposed by Aaronson and Liu. ${ }^{11)}$ Although a relatively small number of parameters are used, the kinetics in the binary $\mathrm{Pb}-\mathrm{Sn}$ system is satisfactorily reproduced by the Aaronson and Liu (AL) model. ${ }^{11)}$ The moving cell boundary for the cell consisting of the $\gamma$ and $\alpha$ lamellae is schematically shown in Fig. 8. According to the AL model, the migration rate $v$ of the moving cell boundary for the discontinuous precipitation in the binary $\mathrm{Ni}-\mathrm{Cr}$ system is related with the interlamellar spacing $s$ by the following equation.

$$
v=\frac{4 \delta D_{i}^{\mathrm{b}}\left(x_{\mathrm{p}}-x_{\mathrm{m}}\right)}{s^{2}\left(x_{\mathrm{p}}-x_{0}\right)}
$$

Here, $D_{i}^{\mathrm{b}}$ is the boundary diffusion coefficient of solute $i$ along the moving cell boundary, $\delta$ is the thickness of the moving cell boundary, $x_{0}$ is the mol fraction of solute $i$ in the untransformed $\gamma_{0}$ matrix, $x_{\mathrm{p}}$ is that in the $\alpha$ lamella, and $x_{\mathrm{m}}$ is that in the untransformed $\gamma_{0}$ matrix just ahead the $\alpha$ lamella. Here, $i=\mathrm{Cr}$ for the binary $\mathrm{Ni}-\mathrm{Cr}$ system. In Fig. 8, the thickness of the moving cell boundary is exaggerated to emphasize the boundary diffusion rate-controlling process. Equation (5) is expressed in a different manner as follows.

$$
D_{i}^{\mathrm{b}}=\frac{s^{2} v\left(x_{\mathrm{p}}-x_{0}\right)}{4 \delta\left(x_{\mathrm{p}}-x_{\mathrm{m}}\right)}
$$

As previously mentioned, the AL model was proposed for discontinuous precipitation in binary alloy systems. ${ }^{11)}$ As shown in Table 2, however, $x_{X}^{0}$ is merely 0.01 for alloys A2-A4. Therefore, we may expect that the AL model is conveniently used to analyze quantitatively the discontinuous precipitation in the ternary $\mathrm{Ni}-\mathrm{Cr}-X$ system as long as the cell growth is controlled by the boundary diffusion of $\mathrm{Cr}$ along the moving cell boundary. The chemical composition of the $\gamma / \alpha$ two-phase tie-line passing through the composition $x_{i}^{0}$ in Table 2 was calculated by the Calphad technique reported in a previous study. ${ }^{28)}$ The results at $T=873-$ $1023 \mathrm{~K}$ for alloys A1-A4 are shown in Table 3. In this table, $x_{i}^{\gamma}$ and $x_{i}^{\alpha}$ indicate the mol fractions of component $i$ in the $\gamma$ and $\alpha$ phases, respectively, for the $\gamma / \alpha$ two-phase tie-line. If the local equilibrium is realized at the moving cell boundary between the $\gamma_{0}$ matrix and the $\alpha$ lamella, $x_{\mathrm{m}}=x_{i}^{\gamma}$ and $x_{\mathrm{p}}=x_{i}^{\alpha}$ in Fig. 8. Using the mean values of $v$ and $s$ in Figs. 6 and 7 and the relationships $x_{\mathrm{m}}=x_{\mathrm{Cr}}^{\gamma}, x_{\mathrm{p}}=x_{\mathrm{Cr}}^{\alpha}$ and $x_{0}=x_{\mathrm{Cr}}^{0}$, the boundary diffusion coefficient $D_{\mathrm{Cr}}^{\mathrm{b}}$ of $\mathrm{Cr}$ was calculated from eq. (6). In this calculation, the value $\delta=0.5 \mathrm{~nm}$ was adopted. The results for alloys A1, A2, A3 and A4 are plotted as open circles, triangles, squares and rhombuses, respectively, against the annealing temperature $T$ in Fig. 9. In this figure, the ordinate shows the logarithm of $D_{\mathrm{Cr}}^{\mathrm{b}}$, and the abscissa indicates the reciprocal of $T$. As can be seen, the plotted points lie well on a straight line for each alloy. Thus, for $i=\mathrm{Cr}$, the dependence of $D_{i}^{\mathrm{b}}$ on $T$ is expressed as follows.

$$
D_{i}^{\mathrm{b}}=D_{i 0}^{\mathrm{b}} \exp \left(-\frac{Q}{R T}\right)
$$

Here, $D_{i 0}^{\mathrm{b}}$ is the pre-exponential factor, $Q$ is the activation enthalpy, and $R$ is the gas constant. From the plotted points in Fig. $9, D_{\mathrm{Cr} 0}^{\mathrm{b}}$ and $Q$ for $D_{\mathrm{Cr}}^{\mathrm{b}}$ were estimated by the leastsquares method as shown with solid lines. The estimated values are indicated in Fig. 9. As can be seen, $D_{\mathrm{Cr}}^{\mathrm{b}}$ is lightly greater for alloy A2 than for alloy A1 but smaller for alloys A3 and A4 than for alloys A1 and A2. At lower annealing temperatures, $D_{\mathrm{Cr}}^{\mathrm{b}}$ becomes slightly smaller for alloy A4 than for alloy A3. Therefore, it is concluded that the boundary diffusion of $\mathrm{Cr}$ along the moving cell boundary is decelerated by $\mathrm{W}$ and Mo but marginally accelerated by Fe. The deceleration effect is more remarkable for Mo than for W. In Fig. 9, the corresponding results of alloys A5, A6 and A $7^{15)}$ are shown as thin dotted, dashed and dashed-and-dotted lines, respectively. For alloys $\mathrm{A} 5-\mathrm{A} 7, D_{\mathrm{Cr}}^{\mathrm{b}}$ monotonically increases with increasing $\mathrm{Cr}$ concentration. Consequently, the increase in the $\mathrm{Cr}$ concentration causes acceleration of the cell growth in the binary $\mathrm{Ni}-\mathrm{Cr}$ system. On the other hand, $Q=185$ and $219^{15)} \mathrm{kJ} / \mathrm{mol}$ for alloys A1 and A5, respectively. Hence, at first glance, $Q$ is slightly greater for alloy A5 than for alloy A1. Between alloys A1 and A5, there exist certain differences of $v$ and $s$ in Figs. 6 and 7, respectively. Although these differences may yield dissimilarity in $D_{\mathrm{Cr}}^{\mathrm{b}}$ through eq. (6), the resultant values of $D_{\mathrm{Cr}}^{\mathrm{b}}$ are rather close to each other between alloys A1 and A5 in Fig. 9. Furthermore, $v$ and $s$ possess experimental uncertainty as shown with the error bars in Figs. 6 and 7, respectively. Such uncertainty influences accuracy for the estimation of $D_{\mathrm{Cr}}^{\mathrm{b}}$. Since $Q$ corresponds to the slope of $D_{\mathrm{Cr}}^{\mathrm{b}}$ in Fig. 9, the estimation accuracy is much lower for $Q$ than for $D_{\mathrm{Cr}}^{\mathrm{b}}$. As a consequence, in the present article, attention is focused on the absolute value of $D_{\mathrm{Cr}}^{\mathrm{b}}$ but not on the slope of $D_{\mathrm{Cr}}^{\mathrm{b}}$.

For the calculation in Fig. 9, it is assumed that the local equilibrium is realized at the moving cell boundary between the $\gamma_{0}$ matrix and the $\alpha$ lamella. According to the calculation, Mo and $\mathrm{W}$ decelerate the boundary diffusion of $\mathrm{Cr}$ along the moving cell boundary. This implies that the boundary 
Table 3 Chemical compositions $x_{i}^{\gamma}$ and $x_{i}^{\alpha}$ for the $\gamma / \alpha$ two-phase tie-line passing through the composition $x_{i}^{0}$ in Table 2. The values of $r$ calculated from eq. (8) are also shown at the last column.

\begin{tabular}{|c|c|c|c|c|c|c|c|c|c|}
\hline \multirow{2}{*}{ Alloy } & \multirow{2}{*}{$X$} & \multirow{2}{*}{$T / \mathrm{K}$} & \multicolumn{3}{|c|}{$\gamma$} & \multicolumn{3}{|c|}{$\alpha$} & \multirow{2}{*}{$r$} \\
\hline & & & $x_{\mathrm{Ni}}^{\gamma}$ & $x_{\mathrm{Cr}}^{\gamma}$ & $x_{X}^{\gamma}$ & $x_{\mathrm{Ni}}^{\alpha}$ & $x_{\mathrm{Cr}}^{\alpha}$ & $x_{X}^{\alpha}$ & \\
\hline \multirow[t]{4}{*}{$\mathrm{A} 1$} & - & 873 & 0.6828 & 0.3172 & - & 0.0029 & 0.9971 & - & 0.8532 \\
\hline & & 923 & 0.6672 & 0.3329 & - & 0.0046 & 0.9954 & - & 0.8730 \\
\hline & & 973 & 0.6510 & 0.3490 & - & 0.0069 & 0.9931 & - & 0.8944 \\
\hline & & 1023 & 0.6344 & 0.3656 & - & 0.0102 & 0.9898 & - & 0.9176 \\
\hline \multirow{3}{*}{ A2 } & & 923 & 0.6608 & 0.3290 & 0.0103 & 0.0045 & 0.9941 & 0.0014 & 0.8680 \\
\hline & & 973 & 0.6447 & 0.3453 & 0.0100 & 0.0069 & 0.9914 & 0.0017 & 0.8894 \\
\hline & & 1023 & 0.6281 & 0.3621 & 0.0098 & 0.0102 & 0.9878 & 0.0020 & 0.9125 \\
\hline \multirow[t]{3}{*}{ A3 } & W & 873 & 0.6862 & 0.3026 & 0.0113 & 0.0028 & 0.9931 & 0.0041 & 0.8232 \\
\hline & & 923 & 0.6706 & 0.3185 & 0.0109 & 0.0045 & 0.9902 & 0.0053 & 0.8408 \\
\hline & & 973 & 0.6545 & 0.3349 & 0.0106 & 0.0068 & 0.9866 & 0.0066 & 0.8584 \\
\hline \multirow[t]{4}{*}{ A4 } & Mo & 873 & 0.6763 & 0.3126 & 0.0111 & 0.0029 & 0.9947 & 0.0024 & 0.8424 \\
\hline & & 923 & 0.6610 & 0.3281 & 0.0108 & 0.0046 & 0.9926 & 0.0028 & 0.8614 \\
\hline & & 973 & 0.6453 & 0.3442 & 0.0106 & 0.0070 & 0.9898 & 0.0033 & 0.8818 \\
\hline & & 1023 & 0.6291 & 0.3606 & 0.0103 & 0.0103 & 0.9860 & 0.0037 & 0.9039 \\
\hline
\end{tabular}

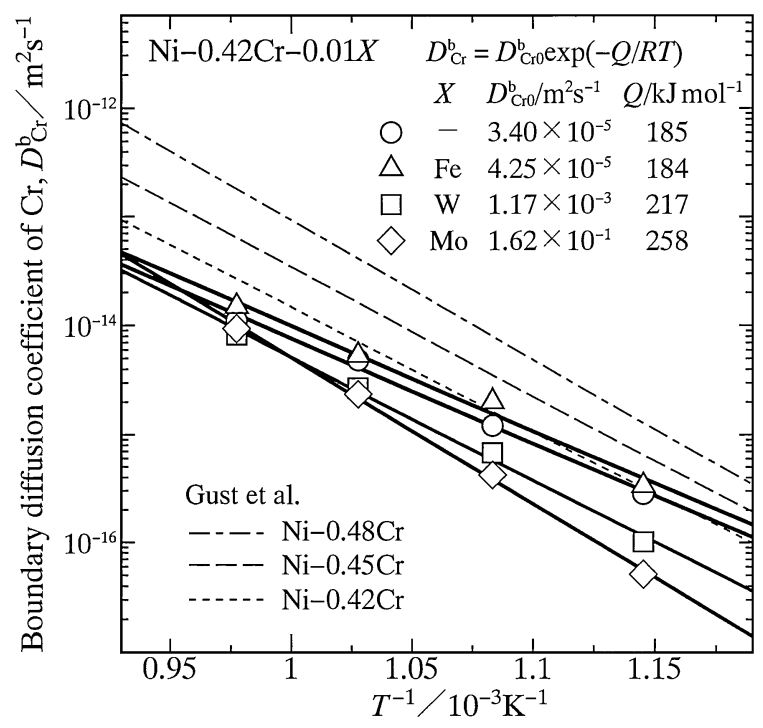

Fig. 9 The boundary diffusion coefficient $D_{\mathrm{Cr}}^{\mathrm{b}}$ of $\mathrm{Cr}$ versus the reciprocal of the annealing temperature $T$ for alloys A1, A2, A3 and A4 shown as open circles, triangles, squares and rhombuses, respectively. Bold solid lines indicate the calculations from eq. (7). The corresponding results of alloys A5, A6 and A $7^{15)}$ are also represented as thin dotted, dashed and dashed-and-dotted lines, respectively.

diffusion is more sluggish for Mo and $\mathrm{W}$ than for Cr. If the boundary diffusion coefficient $D_{X}^{\mathrm{b}}$ of component $X$ is much smaller than $D_{\mathrm{Cr}}^{\mathrm{b}}$, the local equilibrium at the moving cell boundary may be violated. In such a case, the assumption cannot be valid for alloys A2-A4. To test the validity of the assumption, $D_{X}^{\mathrm{b}}$ was estimated from eq. (6) using the mean values of $v$ and $s$ in Figs. 6 and 7 as well as the relationships $x_{\mathrm{m}}=x_{X}^{\gamma}, x_{\mathrm{p}}=x_{X}^{\alpha}$ and $x_{0}=x_{X}^{0}$. The results for $X=\mathrm{Fe}, \mathrm{W}$ and Mo are plotted as open triangles, squares and rhombuses, respectively, against the annealing temperature $T$ in Fig. 10. In this figure, like Fig. 9, the ordinate shows the logarithm of

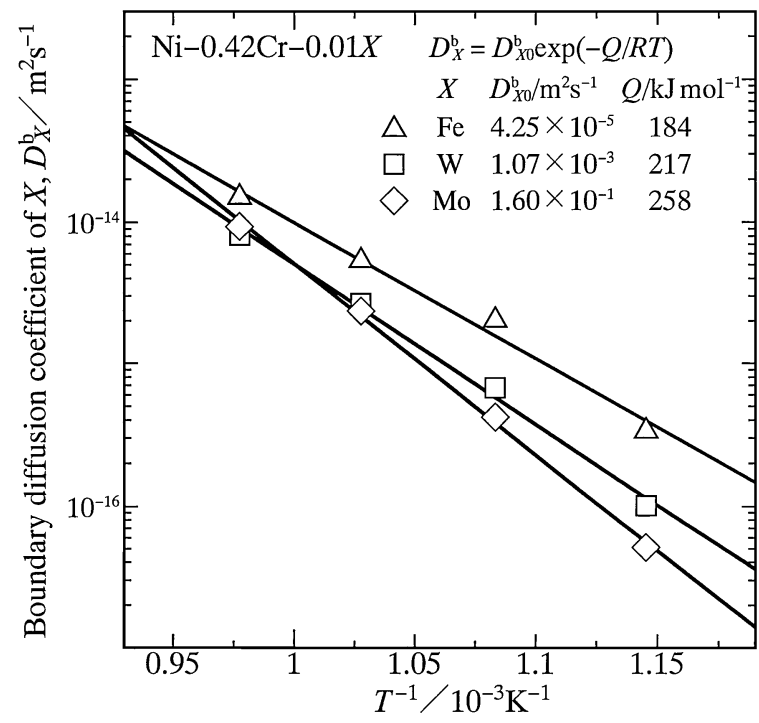

Fig. 10 The boundary diffusion coefficient $D_{X}^{\mathrm{b}}$ of component $X$ versus the reciprocal of the annealing temperature $T$ for $X=\mathrm{Fe}, \mathrm{W}$ and Mo shown as open triangles, squares and rhombuses, respectively. Bold solid lines indicate the calculations from eq. (7).

$D_{X}^{\mathrm{b}}$, and the abscissa indicates the reciprocal of $T$. As can be seen, the plotted points are located well on a straight line for each component $X$. Thus, the dependence of $D_{X}^{\mathrm{b}}$ on $T$ is also expressed by eq. (7). From the plotted points in Fig. 10, $D_{X 0}^{\mathrm{b}}$ and $Q$ were estimated by the least-squares method as shown with the straight lines. At $T=873-1023 \mathrm{~K}, D_{\mathrm{Mo}}^{\mathrm{b}}$ and $D_{\mathrm{W}}^{\mathrm{b}}$ are smaller than $D_{\mathrm{Fe}}^{\mathrm{b}}$. Although $D_{\mathrm{Mo}}^{\mathrm{b}}$ is close to $D_{\mathrm{W}}^{\mathrm{b}}$ at $T=973-1023 \mathrm{~K}$, it becomes slightly smaller than $D_{\mathrm{W}}^{\mathrm{b}}$ at $T=873-923 \mathrm{~K}$. Thus, Mo and $\mathrm{W}$ are actually sluggish diffusion components. As shown in Figs. 9 and 10, however, $D_{\mathrm{Fe}}^{\mathrm{b}}, D_{\mathrm{W}}^{\mathrm{b}}$ and $D_{\mathrm{Mo}}^{\mathrm{b}}$ are close to $D_{\mathrm{Cr}}^{\mathrm{b}}$ for alloys A2, A3 and A4, respectively, at each annealing temperature. Since the same values of $v$ and $s$ in Figs. 6 and 7 are used for both 
calculations of $D_{\mathrm{Cr}}^{\mathrm{b}}$ and $D_{X}^{\mathrm{b}}(X=\mathrm{Fe}, \mathrm{W}, \mathrm{Mo})$, the difference between $D_{\mathrm{Cr}}^{\mathrm{b}}$ and $D_{X}^{\mathrm{b}}$ is attributed to the values of $x_{\mathrm{m}}, x_{\mathrm{p}}$ and $x_{0}$ in eq. (6). From eq. (6), the parameter $r$ is defied as

$$
r=\frac{x_{\mathrm{p}}-x_{0}}{x_{\mathrm{p}}-x_{\mathrm{m}}}
$$

Using the relationships $x_{\mathrm{m}}=x_{\mathrm{Cr}}^{\gamma}, x_{\mathrm{p}}=x_{\mathrm{Cr}}^{\alpha}$ and $x_{0}=x_{\mathrm{Cr}}^{0}$ for $D_{\mathrm{Cr}}^{\mathrm{b}}$ and those $x_{\mathrm{m}}=x_{X}^{\gamma}, x_{\mathrm{p}}=x_{X}^{\alpha}$ and $x_{0}=x_{X}^{0}$ for $D_{X}^{\mathrm{b}}, r$ was calculated from eq. (8). The result is listed at the last column in Table 3. At each annealing temperature, $r$ is not so dissimilar to one another among alloys A1-A4, and thus $D_{\mathrm{Cr}}^{\mathrm{b}}$ and $D_{X}^{\mathrm{b}}$ are predominantly determined by $v$ and $s$. As a result, $D_{\mathrm{Fe}}^{\mathrm{b}}, D_{\mathrm{W}}^{\mathrm{b}}$ and $D_{\mathrm{Mo}}^{\mathrm{b}}$ become close to $D_{\mathrm{Cr}}^{\mathrm{b}}$ for alloys $\mathrm{A} 2, \mathrm{~A} 3$ and $\mathrm{A} 4$, respectively. Therefore, as long as the $\mathrm{AL}$ model ${ }^{11)}$ is valid for the estimation of $D_{\mathrm{Cr}}^{\mathrm{b}}$ and $D_{X}^{\mathrm{b}}$, we may consider that the boundary diffusion concurrently occurs between $\mathrm{Cr}$ and component $X$ in alloys A2-A4.

\subsection{Thermodynamic influence on diffusion}

Thermodynamic influence of a third component on the diffusion of a second component in a ternary solution phase is discussed by Kirkaldy and Young. ${ }^{29)}$ According to their discussion, ${ }^{29)}$ the diffusion coefficient of the second component increases for the attractive thermodynamic interaction between the second and third components but decreases for the repulsive thermodynamic interaction. The moving cell boundary is considered to be a separate thermodynamic phase with a certain thickness. ${ }^{30)}$ If the thermodynamic properties of the second and third components in the moving cell boundary are known, the thermodynamic influence may be quantitatively estimated. Unfortunately, however, no reliable information is available for such thermodynamic properties. Since the atomic arrangement is more disordered in the moving cell boundary than in the fcc- $\gamma$ and bcc- $\alpha$ phases, the thermodynamic property of each component in the moving cell boundary may be similar to that in the liquid (L) phase. The most predominant thermodynamic interaction between $\mathrm{Cr}$ and component $X(X=\mathrm{Fe}, \mathrm{W}, \mathrm{Mo})$ in the $\mathrm{L}$ phase is expressed by the following equation. ${ }^{31)}$

$$
{ }^{\mathrm{E}} G_{\mathrm{m}}=x_{\mathrm{Cr}} x_{X} L_{\mathrm{Cr} X}
$$

Here, ${ }^{\mathrm{E}} G_{\mathrm{m}}$ is the excess molar Gibbs energy, and $L_{i j}$ is the interaction parameter between components $i$ and $j$. Since $x_{i}$ is dimensionless, $L_{i j}$ as well as ${ }^{\mathrm{E}} G_{\mathrm{m}}$ possesses a dimension of $\mathrm{J} / \mathrm{mol}$. The composition dependence of $L_{i j}$ is described according to a Redlich-Kister polynomial as follows. ${ }^{32)}$

$$
\begin{aligned}
L_{i j} & ={ }^{0} L_{i j}+{ }^{1} L_{i j}\left(x_{i}-x_{j}\right)+{ }^{2} L_{i j}\left(x_{i}-x_{j}\right)^{2} \\
i & =\mathrm{Cr} ; j=\mathrm{Fe}, \mathrm{Mo}, \mathrm{W}
\end{aligned}
$$

The parameter ${ }^{k} L_{i j}(k=0,1,2)$ is usually a function of the temperature $T$. The values of ${ }^{k} L_{i j}$ in the binary $\mathrm{Cr}-\mathrm{Fe},{ }^{33)}$ $\mathrm{Cr}-\mathrm{Mo}^{34)}$ and $\mathrm{Cr}-\mathrm{W}^{35)}$ systems are summarized in Table 4. Using the values in Table 4, the dependence of ${ }^{\mathrm{E}} G_{\mathrm{m}}$ on $T$ at $x_{X}=0.01\left(x_{\mathrm{Cr}}=0.99\right)$ was calculated from eqs. (9) and (10). The results for $X=\mathrm{Fe}, \mathrm{W}$ and Mo are shown as dotted, dashed and solid curves, respectively, in Fig. 11. At $T=$ $873-1023 \mathrm{~K},{ }^{\mathrm{E}} G_{\mathrm{m}}$ is negative for $X=\mathrm{Fe}$ but positive for $X=\mathrm{W}$ and Mo. Furthermore, ${ }^{\mathrm{E}} G_{\mathrm{m}}$ is greater for $X=\mathrm{Mo}$ than for $X=\mathrm{W}$. This means that the thermodynamic interaction between $\mathrm{Cr}$ and $X$ is attractive for $X=\mathrm{Fe}$ but
Table 4 Values of ${ }^{k} L_{i j}$ for the liquid phase in the binary $\mathrm{Cr}-\mathrm{Fe},{ }^{33)} \mathrm{Cr}-\mathrm{Mo}^{34)}$ and $\mathrm{Cr}-\mathrm{W}^{35)}$ systems measured in $\mathrm{J} / \mathrm{mol}$.

$$
\begin{aligned}
& \mathrm{Cr}-\mathrm{Fe} \text { system }{ }^{33)} \\
& { }^{0} L_{\mathrm{CrFe}}=-14550+6.65 T \\
& { }^{1} L_{\mathrm{CrFe}}=0 \\
& { }^{2} L_{\mathrm{CrFe}}=0 \\
& \mathrm{Cr}-\mathrm{Mo} \mathrm{system}{ }^{34)} \\
& { }^{0} L_{\mathrm{CrMo}}=15810-6.714 T \\
& { }^{1} L_{\mathrm{CrMo}}=-6220 \\
& { }^{2} L_{\mathrm{CrMo}}=0 \\
& { }^{\mathrm{Cr}-\mathrm{W}} \text { system } \\
& { }^{0} L_{\mathrm{CrW}}=-16800+10 T \\
& { }^{1} L_{\mathrm{CrW}}=9000 \\
& { }^{2} L_{\mathrm{CrW}}=0
\end{aligned}
$$

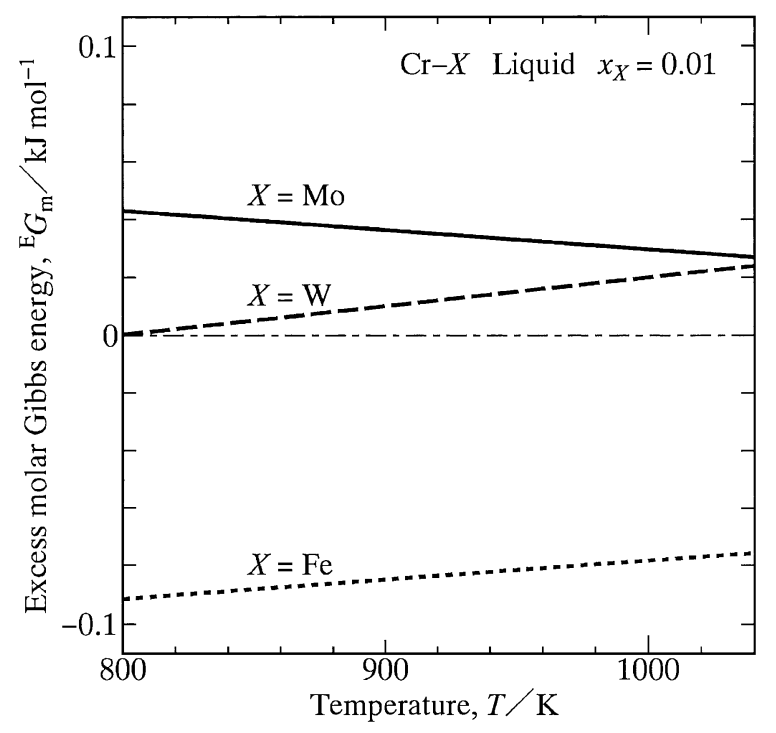

Fig. 11 The excess molar Gibbs energy ${ }^{\mathrm{E}} G_{\mathrm{m}}$ at $x_{X}=0.01$ versus the temperature $T$ for $X=\mathrm{Fe}, \mathrm{W}$ and Mo shown as dotted, dashed and solid curves, respectively.

repulsive for $X=\mathrm{W}$ and Mo. The repulsive interaction is more remarkable for $X=$ Mo than for $X=\mathrm{W}$. According to the result in Fig. $10, D_{\mathrm{W}}^{\mathrm{b}}$ is smaller than $D_{\mathrm{Fe}}^{\mathrm{b}}$, and $D_{\mathrm{Mo}}^{\mathrm{b}}$ is typically smaller than $D_{\mathrm{W}}^{\mathrm{b}}$. Consequently, as shown in Fig. 9, $D_{\mathrm{Cr}}^{\mathrm{b}}$ is increased by Fe but decreased by $\mathrm{W}$ and Mo. This influence is more notable for $X=$ Mo than for $X=\mathrm{W}$.

\section{Conclusions}

The kinetics of the discontinuous precipitation in the $\mathrm{Ni}-$ $\mathrm{Cr}$ and $\mathrm{Ni}-\mathrm{Cr}-X$ systems was experimentally observed using the $\mathrm{Ni}-38 \mathrm{Cr}, \mathrm{Ni}-38 \mathrm{Cr}-0.9 \mathrm{Fe}, \mathrm{Ni}-38 \mathrm{Cr}-3.2 \mathrm{~W}$ and $\mathrm{Ni}-38 \mathrm{Cr}-$ $1.7 \mathrm{Mo}$ alloys with the single-phase microstructure of the fcc- $\gamma$ phase. These alloys were isothermally annealed at temperatures of $873-1023 \mathrm{~K}$ for various periods up to $2300 \mathrm{~h}$. During isothermal annealing, the discontinuous precipitation of the $\mathrm{Cr}$-rich bcc- $\alpha$ phase takes place in the Ni-rich $\gamma$ matrix. Owing to the discontinuous precipitation, the cell consisting 
of the $\gamma$ and $\alpha$ lamellae is formed along the grain boundary of the $\gamma$ matrix and then grows into the $\gamma$ matrix under steadystate conditions. The growth rate and the interlamellar spacing of the cell mostly monotonically increase with increasing annealing temperature at $873-1023 \mathrm{~K}$. The cell growth is retarded by $\mathrm{W}$ and Mo but not by Fe. The retardation is more remarkable for Mo than for W. A kinetic model for the binary discontinuous precipitation controlled by boundary diffusion was proposed by Aaronson and Liu. ${ }^{11)}$ Their model was used to analyze quantitatively the observation. The analysis shows that the boundary diffusion of $\mathrm{Cr}$ along the moving cell boundary is decelerated by $\mathrm{W}$ and Mo but slightly accelerated by Fe. The thermodynamic interaction between $\mathrm{Cr}$ and the alloying component in the moving cell boundary yields such influence of the alloying component on the boundary diffusion. Therefore, the retardation of the cell growth is attributed to the deceleration of the $\mathrm{Cr}$ boundary diffusion.

\section{Acknowledgements}

The present study was supported by Daido Steel Co., Ltd. The study was also partially supported by a Grant-in-Aid for Scientific Research from the Ministry of Education, Culture, Sports, Science and Technology of Japan.

\section{REFERENCES}

1) K. Shimotori, M. Kawai and H. Tokoro: J. Japan Inst. Metals 36 (1972) 685-692.

2) K. Shimotori, K. Amano and Y. Fukazawa: J. Japan Inst. Metals 36 (1972) 818-825.

3) K. Shimotori, K. Kawaguchi, M. Miyauchi and T. Tomita: J. Japan Inst. Metals 37 (1973) 715-724.

4) P. J. Kujawinski and R. A. Stradling: High Press. Res. 5 (1990) 883885.

5) I. R. Walker: Rev. Sci. Instr. 70 (1999) 3402-3412.
6) Y. Uwatoka, S. Todo, K. Ueda, A. Uchida, M. Kosaka, N. Mori and T. Matsumoto: J. Phys. Condens. Matter 14 (2002) 11291-11296.

7) S. Komatsu, M. Nakahashi, I. Watanabe and K. Shimotori: J. Japan Inst. Metals 40 (1976) 1208-1215.

8) V. A. Petrov, V. F. Sukhovarov and R. D. Strokatov: Izvest. Vyssh. Uch. Zaved. Fiz. 6 (1984) 24-28.

9) M. Kawase, H. Emoto and M. Kikuchi: Proc. Phase Transformations '87, Inst. Met., London, (1988) pp. 254-257.

10) S. Ueta and M. Kajihara: ISIJ Int. 50 (2010) 1676-1682.

11) H. I. Aaronson and Y. C. Liu: Scr. Metall. 2 (1968) 1-7.

12) K. P. Gupta: Phase Diagrams of Ternary Nickel Alloys, Part 1, (ASM International, 1990) p. 26.

13) P. Villars, A. Prince and H. Okamoto: Handbook of Ternary Alloy Phase Diagrams, Vol. 7, (ASM International, 1995) p. 9169.

14) I. Manna, S. K. Pabi and W. Gust: Int. Mater. Rev. 46 (2001) 53-91.

15) W. Gust, T. Nguyen-Tan and B. Predel: Mater. Sci. Eng. 39 (1979) $15-25$

16) S. A. Saltykov: Stereometric Metallography, 2nd ed., (Metallurgizdat, Moscow, 1958) p. 446.

17) C. Zener: Trans. AIME 167 (1946) 550-583

18) D. Turnbull: Acta Metall. 3 (1955) 55-63.

19) J. W. Chan: Acta Metall. 7 (1959) 18-28.

20) K. N. Tu and D. Turnbull: Scr. Metall. 1 (1967) 173-180.

21) J. M. Shapiro and J. S. Kirkaldy: Acta Metall. 16 (1968) 579-585.

22) J. M. Shapiro and J. S. Kirkaldy: Acta Metall. 16 (1968) 1239-1252.

23) J. Petermann and E. Hornbogen: Z. Metallkd. 59 (1968) 814-822.

24) B. E. Sundquist: Acta Metall. 16 (1968) 1413-1427.

25) M. Hillert: Metall. Mater. Trans. B 3 (1972) 2729-2741.

26) B. E. Sundquist: Metall. Mater. Trans. B 4 (1973) 1919-1934.

27) M. Hillert: Acta Metall. 30 (1982) 1689-1696.

28) N. Takahata, S. Ueta and T. Shimizu: Electr. Furn. Steel 75 (2004) 97-105.

29) J. S. Kirkaldy and D. J. Young: Diffusion in the Condensed State, (The Institute of Metals, Carlton House Terrace, London, 1987) p. 236.

30) M. Hillert: Lectures on the Theory of Phase Transformations, ed. by H. I. Aaronson, (TMS, Warrendale, PA, 1999) pp. 1-33.

31) M. Hillert and L.-I. Staffansson: Acta Chem. Scand. 24 (1970) 36183626.

32) M. Hillert: Computer Modeling of Phase Diagrams, ed. by L. H. Bennett, (TMS-AIME, Warrendale, PA, 1986) pp. 1-17.

33) J.-O. Andersson and B. Sundman: Calphad 11 (1987) 83-92.

34) K. Frisk: Report D 60, Royal Inst. Tech., Sweden, (1984).

35) K. Frisk and P. Gustafson: Calphad 12 (1988) 247-254. 